\title{
Modelling and simulation of a waste sorting mechatronic system for multi-floor residential buildings
}

\author{
Liviu-Marian Ungureanu, ${ }^{1, *}$, Ileana Dugăeșescu ${ }^{1}$ and Elisabeta Niculae ${ }^{1}$ \\ ${ }^{1}$ University Politehnica of Bucharest, Theory of Mechanisms and Robots Department, RO-060042 \\ Splaiul Independentei, No.313 room JC111, Romania
}

\begin{abstract}
The paper presents modelling and simulation of a mechatronic sorting system for residential buildings where the "wet" garbage can be used as fuel in an energy generation system. The proposed system can be used for the implementation of a selective storage model in the actual garbage chute system. The proposed system will have five different storage capacities that can be recycled: paper, glass, plastic packaging, metal boxes and organic household waste.
\end{abstract}

\section{Introduction}

Waste collection is not done at source; instead, the garbage is thrown through a garbage chute system, where reaches the garbage storage room on the ground floor of the building from where it is loaded manually into garbage collection machines. Also, storage is a real problem [1-8] and in this paper, we present a solution that enhance actual systems for a selective, sorting and storage system to obtain selective packages that can be recycled.

In literature, many papers or studies present similar systems for waste management systems implemented in different countries [9-11, 16] dealing with automated sorting systems [12-13]. These solutions have some important disadvantages regarding costs, maintenance and use. Therefore, we propose a low-cost solution for garbage chute system with four or six distinct routes for dumping the waste that can be used in multi-floor residential buildings. The system consists of a garbage chute with door access from each floor and four storage devices for waste placed in a ground room.

The proposed system addresses the issue of selective collection of the following types of waste:

- glass, glass containers made for beverages and food, jars;

- newspapers, magazines, paper-cardboard packaging, folded cardboard boxes;

- plastic packaging, plastic beverage containers (PET) and dairy products. Containers for cosmetics and detergents, plastic and polystyrene cassettes, plastic dishes, noncontaminated household waste plastic bags, plastic food containers;

- metal packaging, such as cans, beverage doses;

* Corresponding author: ungureanu.liviu.marian@gmail.com 
- organic household waste.

According with the legislation, until 2025 [14], all the buildings must have a room on the ground floor, properly arranged, with four special containers for paper, glass, plastic and metal, plus the household. But it is hard to believe that the inhabitants on the upper floors will come down to throw the garbage in the especially designed places. Nevertheless, it will be preferred that the convenient and fast solution as outlined in this paper.

\section{Study on rotation of the mobile waste sorting element}

From the point of view of waste sorting, this study is essential to determine the position of the garbage container. Elements of kinematic modelling of mechanisms were used [15, 17]. The kinematic modelling refers to the fundamental principle of forming mechanisms, according to which a mechanism is made up of an active modular group and a passive modular group, the number and nature of which are dependent on the degree of freedom and the number of independent contours. The degree of mobility puts into evidence the number of independent variables that define the state of motion of the mechanism. The position function is

$$
f_{\mathrm{i}}\left(x_{1}, x_{2} \ldots x_{k} y_{1}, y_{2} \ldots y_{j}\right)=0
$$

where $\mathrm{k}=1 \ldots \mathrm{M}(\mathrm{M}=$ degree of mobility), $j=1 \ldots 2 \mathrm{~N}(2 \mathrm{~N}=$ number equation of independent loop), $x_{k}$ are independent variables and $y_{j}$ are dependent variables.

From Eq. 1 using derivation in function of time results the velocity.

$$
\sum \frac{\partial \mathrm{f}_{\mathrm{i}}}{\partial \mathrm{x}_{\mathrm{k}}} \dot{\mathrm{x}}_{\mathrm{k}}+\sum \frac{\partial \mathrm{f}_{\mathrm{i}}}{\partial \mathrm{y}_{\mathrm{j}}} \dot{\mathrm{y}}_{\mathrm{j}}=0
$$

We can rewrite Eq. 2 as

$$
\mathrm{A}\left\|\dot{\mathrm{y}}_{\mathrm{j}}\right\|=\mathrm{B}
$$

Where

$$
\mathrm{A}=\left\|\frac{\partial \mathrm{f}_{\mathrm{i}}}{\partial \mathrm{y}_{\mathrm{j}}}\right\| \quad \mathrm{B}=\left\|-\frac{\partial \mathrm{f}_{\mathrm{i}}}{\partial \mathrm{x}_{\mathrm{k}}} \dot{\mathrm{x}_{\mathrm{k}}}\right\|
$$

From Eq. 2 using derivation in function of time results the acceleration.

$$
\sum \frac{\partial f_{i}}{\partial x_{k}} \ddot{x_{k}}+2 \sum \sum \frac{\partial^{2} f_{i}}{\partial x_{k} \partial y_{j}} \dot{x_{k}} \dot{y}_{j}+\sum \frac{\partial f_{i}}{\partial y_{j}} \ddot{y}_{j}+\sum \sum \frac{\partial^{2} f_{i}}{\partial y_{j} \partial y_{k}} \dot{x_{k}} \dot{y}_{j}=0
$$

We can rewrite Eq. 5 as

$$
\mathrm{A}\left\|\dot{\mathrm{y}}_{\mathrm{j}}\right\|=\mathrm{C} ; \quad C=\left\|\sum \frac{\partial \mathrm{f}_{\mathrm{i}}}{\partial \mathrm{x}_{\mathrm{k}}} \ddot{\mathrm{x}_{\mathrm{k}}}+2 \sum \sum \frac{\partial^{2} \mathrm{f}_{\mathrm{i}}}{\partial \mathrm{x}_{\mathrm{k}} \partial \mathrm{y}_{\mathrm{j}}} \dot{\mathrm{x}_{\mathrm{k}}} \dot{\mathrm{y}}_{\mathrm{j}}+\sum \sum \frac{\partial^{2} \mathrm{f}_{\mathrm{i}}}{\partial \mathrm{y}_{\mathrm{j}} \partial \mathrm{y}_{\mathrm{k}}} \dot{\mathrm{x}_{\mathrm{k}}} \dot{\mathrm{y}}_{\mathrm{j}}\right\|
$$

Using the above relationships, several trajectories of the mobile waste sorting element were determined using a numerical software.

The mechanism of waste sorting is presented in Fig.1 and the trajectory will be generated by the mobile sorting element at different rotation angles in Fig. 2. 


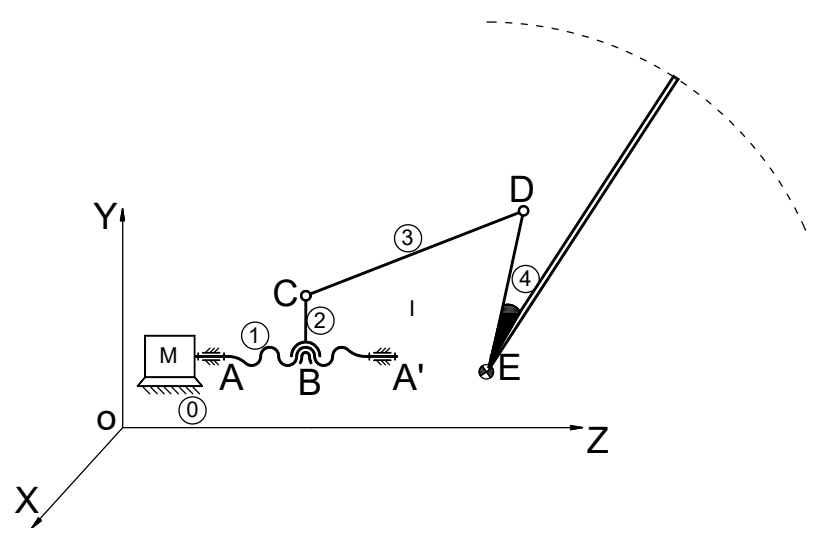

Fig. 1. Mechanism of waste sorting.

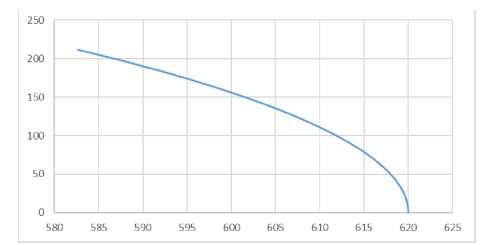

a)

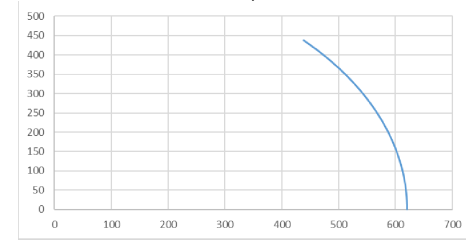

c)

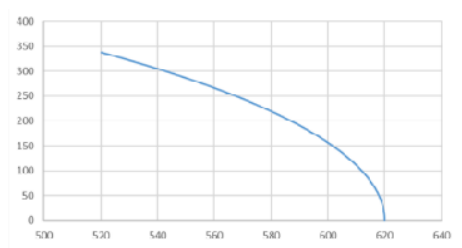

b)

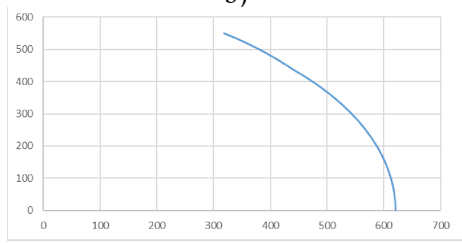

d)

Fig. 2. Trajectory of the mobile sorting element at different rotation angles: a) $20^{\circ}$; b) $30^{\circ}$; c) $45^{\circ}$; d) $60^{\circ}$.

\section{Modelling and simulation of a mechanical waste sorting system}

The mechanical waste sorting system is made of five slots for: glass (green); metals (yellow); plastic (red); paper (blue) and household waste (the free fall section) as can be seen in Fig 3. 


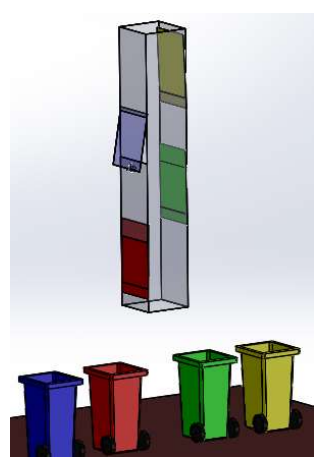

a)

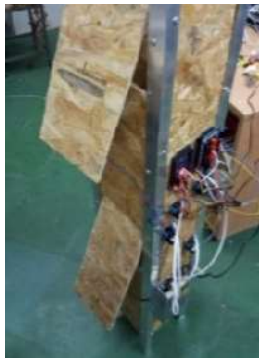

b)

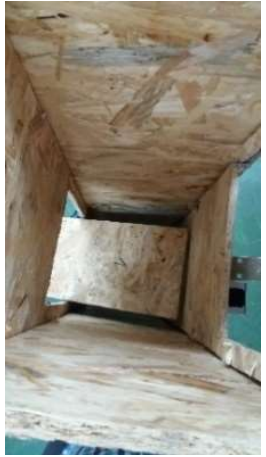

c)

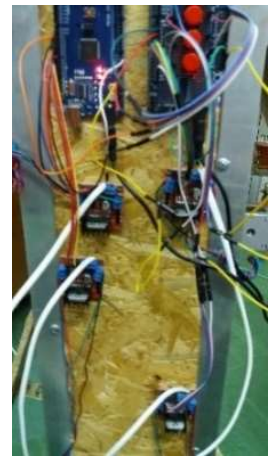

d)

Fig. 3. The prototype : a) CAD Model, b) realized small-scale model, c) top view, d) electronic part.

For kinematic modelling, it was used a 3D simulation software, before that it was realized each part and then combined into an assembly, resulting the desired waste sorting system.

In Fig. $4 \mathrm{~b}$ we present how it was simulated the minimum and the maximum trajectory of garbage (interrupted line), to place the garbage container within these limits. The fixed place where the garbage container is located could not be established, as there are several variables regarding the waste: weight, density and form, but there are some tests in progress and the results will be included in a future study.

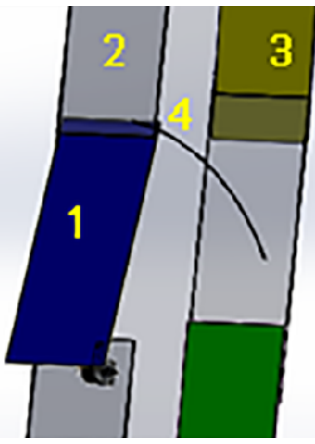

a)

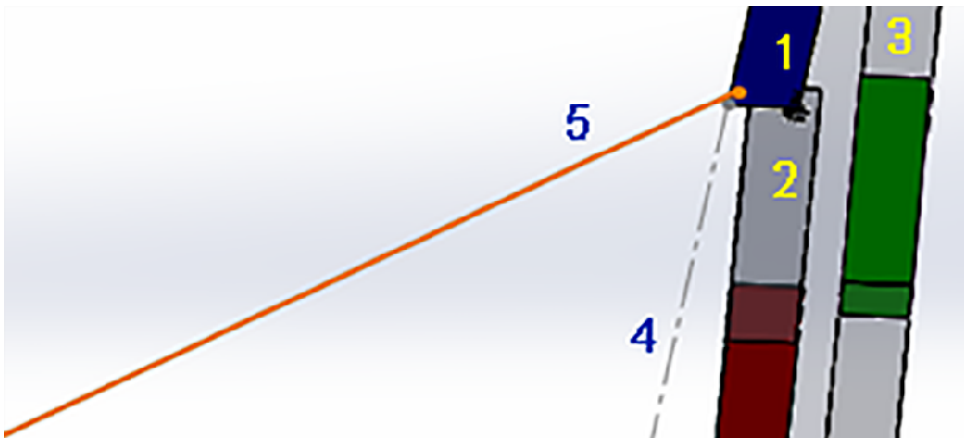

b

Fig. 4. Mobile sorting element: a) trajectory of the mobile sorting element (1-door; 2- front wall; 3back door; 4 - trajectory), b) trajectory of the place garbage container (1-door; 2- front wall; 3- back door, 4 - minimum trajectory of garbage; 5 - maximum trajectory of garbage).

To see if the elements of the garbage selection system can take a specified load there was realized several FEM analyses. 


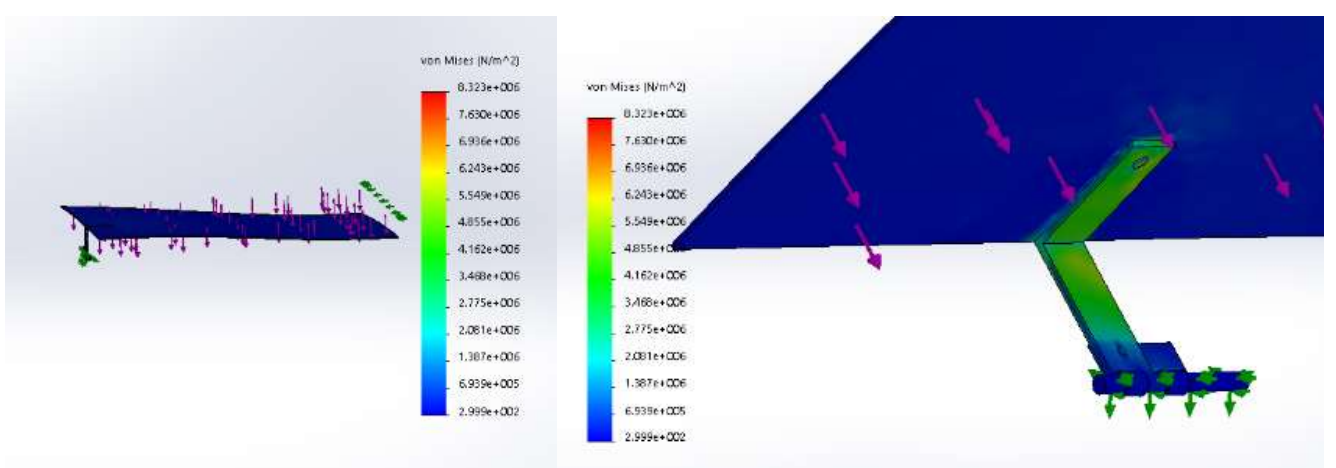

a)

b)

Fig. 5. Mechanical stress obtained through the simulations: a) Mechanical load on the mobile sorting element; b) Mechanical load on the gripping element.

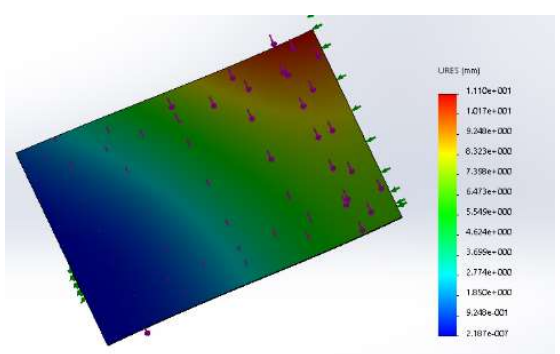

Fig. 6. Deformation of the mobile sorting element obtained using FEM.

These were focused on the actuation system and on the door. A $10 \mathrm{~N}$ load is considered as constantly distributed over the sorting element, a sliding element at the side edge opposite the clamping member and a rotating element at the shaft of the engine (Fig, 5a and 5b). This is the most disadvantageous case where the entire load will fall on the engine spindle (which should not happen accidentally), for that mechanism of waste sorting has a screw nut elements. The deformation of the mobile sorting element is present in Fig.6. The second simulation considered a concentrate force of $10 \mathrm{~N}$ placed in the middle of the structure that is the most disadvantageous situation (Fig, 7a and 7b).

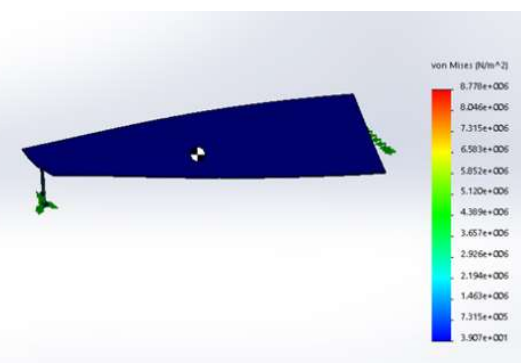

a)

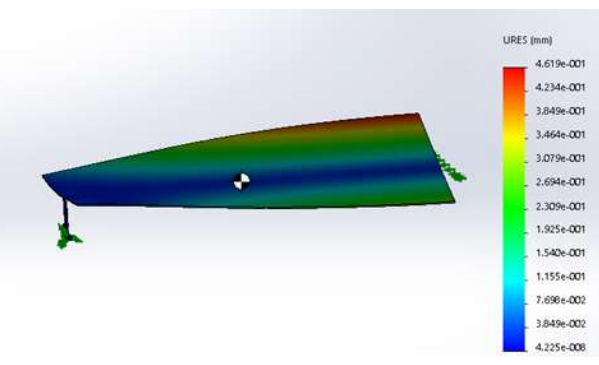

b)

Fig. 7. Results of the FEM simulation when a force of $10 \mathrm{~N}$ is placed in middle of the clamp: a) Mechanical stress; b) Mechanical deformation.

As can be seen in Fig 7, the greatest deformation of the mobile sorting element occurs at the location where the element takes directly the weight of the trash. The maximum 
deformation of the mobile sorting element appears at the contact between the selector margin and the garbage chute. This is due to the unbalanced attachment to the gripping element. In order to be verify model we have developed a small-scale model of the mechanical sorting system because the solution needs a coherent approach to deliver a workable technical solution. This experimental model was imperative to implement the control and the electronic part of the mechanical sorting system.

The prototype (Fig. 2) is using four step motors type 42BYGHW609 with a power control done using a L298N driver. The automation of the system was made using the Arduino MEGA 2560 and four control buttons, one for each sort of waste.

\section{Conclusions}

In this article, was presented the 3D modelling and simulation of a mechanical waste sorting system. We verified the mathematical model using a specialized software, and it was realized the kinematic analyze. Also, a finite element analysis was performed to see the static mechanical behavior mobile of the sorting element .

To evaluate the theoretical results, a small-scale model was made which includes the automation software. In the near future, we want to test a real system in the existing system in the residential buildings.

\section{References}

1. L. Tralhao, J. Coutinho-Rodrigues, L. Alcada-Almeida, A multi-objective modeling approach to locate multi-compartment containers for urban-sorted waste, Waste Management, vol. 30, pp.2418-2429, (2010)

2. W. S. Lu, H.P. Yuan, Exploring critical success factors for waste management in construction projects of China, Resources Conservation and Recycling, vol. 55, pp. 201-208, (2010)

3. D. Mickael, D. Isabelle, M. Sebastien, A review of literature: Influence and communication applied to waste management, Pratiques Psychologiques, vol. 20, pp. 211-230, (2014)

4. V. Yadava, A. K. Bhurjeed, S. Karmakara, A. K. Dikshit, A facility location model for municipal solid waste management system under uncertain environment, Science of the Total Environment, vol. 603-604, pp. 760-771, (2017)

5. Y. L. Liu, P. X. Xing, J. G. Liu, Environmental performance evaluation of different municipal solid waste management scenarios in China, Resources Conservation and Recycling, vol. 125, pp 98-106, (2017)

6. G. Aid, M. Eklund, S. Anderberg, L. Baas, L, Expanding roles for the Swedish waste management sector in interorganizational resource management, Resources Conservation and Recycling vol. 124, pp. 85-97, (2017)

7. S. Moon, S. Han, P.R. Zekavat, L. E. Bernold, X. Wang, Process-waste reduction in the construction supply chain using proactive information network, Concurrent Engineering-Research and Applications, vol. 25, pp. 123-135, (2017)

8. M. Kelly, D. Dowd, A review of construction waste management practices on selected case studies in Ireland, Proceedings of the Institution of Civil Engineers-Waste and Resource Management, vol. 170, pp. 78-84, (2017)

9. J. Winkler, B. Bilitewski, Comparative evaluation of life cycle assessment models for solid waste management, Waste Management, vol. 27, pp. 1021-1031, (2007) 
10. A. Bernstad, J. L. Jansen, Review of comparative LCAs of food waste management systems - Current status and potential improvements, Waste Management, vol. 32, pp. 2439-2455, (2012)

11. Z. Z. Wu, L. Y. Shen, A. T. W. Yu, XL. Zhang, A comparative analysis of waste management requirements between five green building rating systems for new residential buildings, Journal of Cleaner Production, vol. 112, pp. 895-902, (2016)

12. S.P. Gundupalli, S. Hait, A. Thakur, A review on automated sorting of sourceseparated municipal solid waste for recycling, Waste Management, vol. 60, pp. 56-74, (2017)

13. S. G. Paulraj, S. Hait, A. Thakur, Automated Municipal Solid Waste Sorting for Recycling Using A Mobile Manipulator, Proceedings of the ASME International Design Engineering Technical Conferences and Computers and Information in Engineering Conference, Vol 5a, (2016)

14. Directive 2008/98/EC of the European Parliament and of the Council of 19 November 2008 on waste

15. A. Comănescu, D. Comănescu, I. Dugăeşescu, A. Boureci, Bazele modelării mecanismelor, Politehnica Press, pp 29-30, (2010)

16. T. Prisecaru, A. Semenescu, C.D. Comeaga, C. G. Alionte, "Experimental integrated system used for combustion process and resulted flue gas analysis", Metalurgia International, 14 (7), pp. 36-42, ISSN 1582-221, 2009

17. R. Mihai, L. A. Cartal, C. G. Alionte, T. C. Apostolescu, The development of an electrical actuated planar parallel robot, Romanian Review Precision Mechanics, Optics and Mechatronics, 44, pp. 120-124 